\title{
Sputtering pressure influenced structural, electrical and optical properties of RF magnetron sputtered $\mathrm{MoO}_{3}$ films
}

\author{
S. Subbarayudu ${ }^{1, *}$, K. Venkata Subba Reddy ${ }^{1}$, S. Uthanna ${ }^{2}$ \\ ${ }^{1}$ Department of Physics, S.B.V.R. Degree College, Badvel-516 227, India \\ ${ }^{2}$ Department of Physics, Sri Venkateswara University, Tirupati-517 502, India
}

\begin{abstract}
$\mathrm{MoO}_{3}$ films were deposited by RF magnetron sputtering technique on glass and silicon substrates held at $473 \mathrm{~K}$ by sputtering of metallic molybdenum target at an oxygen partial pressure of $4 \times 10^{-2} \mathrm{~Pa}$ and at different sputtering pressures in the range of $2 \mathrm{~Pa}$ to $6 \mathrm{~Pa}$. The influence of sputtering pressure on the structure and surface morphology, electrical and optical properties of the $\mathrm{MoO}_{3}$ thin films was studied. X-ray diffraction studies suggest that the films deposited at a sputtering pressure of $2 \mathrm{~Pa}$ were polycrystalline in nature with mixed phase of $\alpha$ - and $\beta$-phase $\mathrm{MoO}_{3}$, while those formed at sputtering pressure of $4 \mathrm{~Pa}$ and above were of $\alpha$-phase $\mathrm{MoO}_{3}$. Scanning electron micrographs showed a decrement in the size of the particles and their shapes changed from needle like structure to dense films with the increase of sputtering pressure. Fourier transform infrared spectroscopic studies confirmed the presence of characteristic vibration modes of $\mathrm{Mo}=\mathrm{O}$, Mo-O and Mo-O-Mo related to $\mathrm{MoO}_{3}$. Electrical resistivity of the $\mathrm{MoO}_{3}$ films decreased from $6.0 \times 10^{4} \Omega \cdot \mathrm{cm}$ to $2 \times 10^{4} \Omega \cdot \mathrm{cm}$ with an increase of sputtering pressure from $2 \mathrm{~Pa}$ to $6 \mathrm{~Pa}$, respectively. Optical band gap of the films decreased from $3.12 \mathrm{eV}$ to $2.86 \mathrm{eV}$ with the increase of sputtering pressure from $2 \mathrm{~Pa}$ to $6 \mathrm{~Pa}$, respectively.
\end{abstract}

Keywords: $\mathrm{MoO}_{3}$ thin films; RF magnetron sputtering; sputtering pressure; structural properties; optical properties

\section{Introduction}

In recent years, much attention has been focused on the technological use of molybdenum oxide $\left(\mathrm{MoO}_{3}\right)$ thin films for device applications because of their structural, electrical and optical properties. Molybdenum oxide in thin film form exists in orthorhombic $\alpha$-phase, monoclinic $\beta$-phase and hexagonal structure. Among these phases, orthorhombic $\alpha$-phase is the most stable. In this phase, the $\mathrm{Mo}^{6+}$ ion is linked to three oxygen atoms in a strongly distorted octahedral environment. $\mathrm{MoO}_{3}$ in thin film form is a potential candidate for sensing of ethanol, ammonia, oxygen, carbon monoxide and nitrogen oxide gases [1-8], solid state microbatteries $[9,10]$, catalysis $[11,12]$, electrochromic devices [13-15], solar cells [16-18] and light emitting diodes [19-21]. Physical properties of $\mathrm{MoO}_{3}$ films depend mainly on the structure and surface morphology as well as an excess or deficient oxygen which controls the electrical

*E-mail: srsuguru.phy@gmail.com and optical properties. Various thin film deposition techniques, namely thermal evaporation $[18,22-$ 24], electron beam evaporation [25], pulsed laser deposition [26, 27], chemical vapor deposition [7], electrodeposition [28, 29], spray pyrolysis [30-33], sol-gel process [8, 34-36], DC magnetron sputtering [37-39] and RF magnetron sputtering [2, 4042] have been used for the preparation of $\mathrm{MoO}_{3}$ thin films. Physical properties of deposited films critically depend on the deposition method and the process parameters fixed during the growth of the films. Among these techniques, RF magnetron sputtering is a versatile method for deposition of $\mathrm{MoO}_{3}$ films on large area and at low substrate temperatures. In RF magnetron sputtering, physical properties of the films mainly depend on the sputtering parameters, such as oxygen partial pressure, substrate temperature, bias voltage, sputtering power and sputtering pressure. The postdeposition annealing leads to a change in the structure, electrical and optical properties. A precise control of the deposition conditions leads to the growth of films with required physical properties. 
In our earlier paper, the influence of annealing temperature on the structural and optical properties of RF magnetron sputtered $\mathrm{MoO}_{3}$ films was reported [42]. In the present investigation, $\mathrm{MoO}_{3}$ films were deposited by $\mathrm{RF}$ reactive magnetron sputtering of metallic target of molybdenum at different sputtering pressures in the range of $2 \mathrm{~Pa}$ to $6 \mathrm{~Pa}$. The influence of sputtering pressure on the structural, electrical and optical properties of the deposited $\mathrm{MoO}_{3}$ films was systematically studied.

\section{Experimental}

$\mathrm{MoO}_{3}$ thin films were deposited on glass and silicon substrates by RF magnetron sputtering technique. The sputtering chamber was evacuated by the combination of diffusion pump and rotary pump to achieve an ultimate pressure of $2 \times 10^{-4} \mathrm{~Pa}$. Molybdenum (99.9\% purity) with $50 \mathrm{~mm}$ diameter and $3 \mathrm{~mm}$ thickness was used as a sputtering target for deposition of the experimental films. The magnetron target assembly was used in a sputter down configuration for deposition of the films.

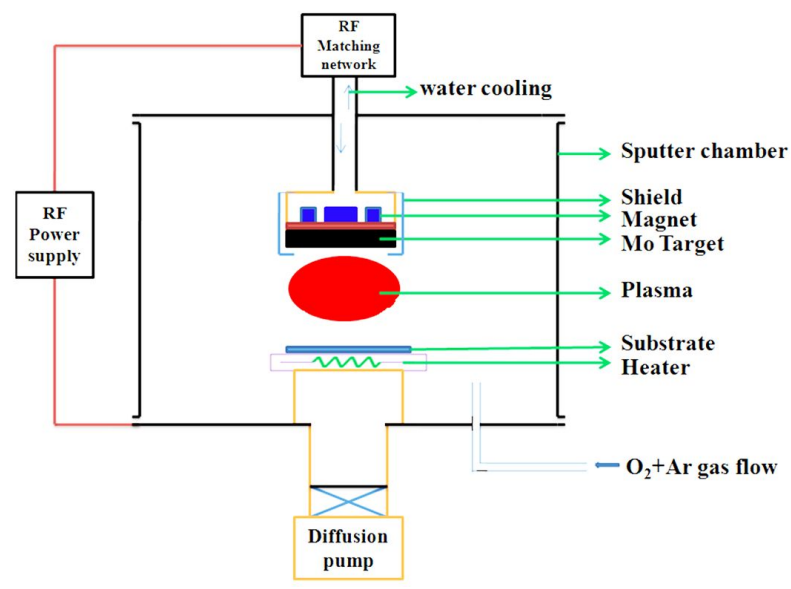

Fig. 1. Schematic diagram of the sputtering chamber.

Fig. 1 shows the schematic diagram of the sputtering chamber employed for deposition of the films. The required quantities of oxygen and argon gases were admitted into the sputtering chamber through fine controlled needle valves. The $\mathrm{MoO}_{3}$ films were deposited on the glass and silicon substrates held at temperature of $473 \mathrm{~K}$ at an oxygen partial pressure of $4 \times 10^{-2} \mathrm{~Pa}$ and at different sputtering pressures in the range from $2 \mathrm{~Pa}$ to $6 \mathrm{~Pa}$. RF power fed to the sputtering target was $150 \mathrm{~W}$. Deposition conditions applied for the preparation of the experimental films are given in Table 1. Thickness of the films was measured using Vecco Dektak depth profilometer. The chemical composition of the films was analyzed using energy dispersive $\mathrm{X}$-ray analysis (Oxford Instruments INCA FETX3). Crystallographic structure of the films was determined with X-ray diffractometer (Seifert X-ray diffractometer Model 3003TT) using $\mathrm{CaK} \alpha$ radiation with a wavelength of $0.15406 \mathrm{~nm}$. The X-ray diffraction profiles were taken in the $2 \theta$ range from $10^{\circ}$ to $50^{\circ}$ with steps of $0.05^{\circ}$. Scanning electron microscope (Carl Zeiss SEM Model EVO MA15) was employed to analyze the surface morphology of the deposited films.

Table 1. Deposition parameters maintained for the growth of $\mathrm{MoO}_{3}$ films

\begin{tabular}{lc}
\hline Sputtering target & Molybdenum $(50 \mathrm{~mm}$ dia. $)$ \\
\hline \hline Ultimate pressure & $4 \times 10^{-4} \mathrm{~Pa}$ \\
Oxygen partial pressure & $4 \times 10^{-2} \mathrm{~Pa}$ \\
Substrate temperature & $473 \mathrm{~K}$ \\
Sputtering pressure & $2 \mathrm{~Pa}$ to $6 \mathrm{~Pa}$ \\
Sputtering power & $150 \mathrm{~W}$ \\
Deposition time & $120 \mathrm{~min}$ \\
Target-substrate distance & $65 \mathrm{~mm}$ \\
\hline
\end{tabular}

The chemical binding configuration of the films deposited on silicon substrates was recorded with Fourier transform infrared spectrophotometer (Nicolet Magna IR 750) in the wavenumber range of $400 \mathrm{~cm}^{-1}$ to $1500 \mathrm{~cm}^{-1}$. The electrical resistivity of the films was measured by employing a standard four probe method. The optical transmittance was recorded on the films deposited on glass substrates using PerkinElmer double beam spectrometer (PerkinElmer Model Lambda 950) in the wavelength range of $300 \mathrm{~nm}$ to $1500 \mathrm{~nm}$ to determine the optical band gap of the films. 


\section{Results and discussion}

\subsection{EDAX spectra}

The thickness of the $\mathrm{MoO}_{3}$ films measured with a depth profilometer was in the range $0.95 \mu \mathrm{m}$ to $1.15 \mu \mathrm{m}$. The chemical composition of the $\mathrm{MoO}_{3}$ films was analyzed with energy dispersive X-ray analysis. Fig. 2 shows the EDAX spectra of the $\mathrm{MoO}_{3}$ films formed at sputtering pressures of $2 \mathrm{~Pa}$ and $4 \mathrm{~Pa}$. From the spectra it is clear that the oxygen content in the films decreased with an increase of sputtering pressure. The film formed at a sputtering pressure of $4 \mathrm{~Pa}$ exhibited atomic ratio of oxygen to molybdenum was 2.96:1. It indicates that the films formed at sputtering pressure of $4 \mathrm{~Pa}$ were composed of $\mathrm{MoO}_{3}$. There was not much variation in chemical composition of the films formed at higher sputtering pressure of $6 \mathrm{~Pa}$.
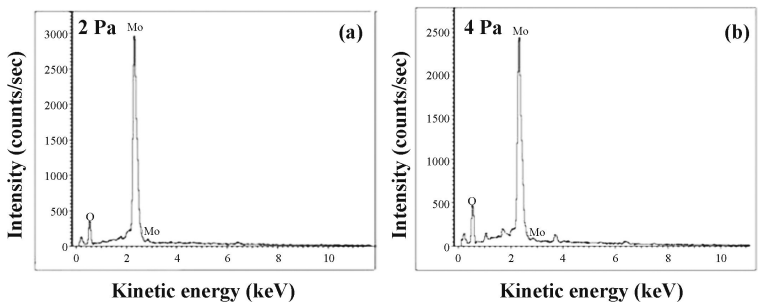

Fig. 2. EDAX spectra of $\mathrm{MoO}_{3}$ films formed at sputtering pressures of (a) $2 \mathrm{~Pa}$ and (b) $4 \mathrm{~Pa}$.

\subsection{Structural properties}

The crystallographic structure of deposited films was analyzed by X-ray diffraction. Fig. 3 shows the X-ray diffraction profiles of $\mathrm{MoO}_{3}$ films deposited at different sputtering pressures. At low sputtering pressure of $2 \mathrm{~Pa}$ the films show the diffraction reflections which indicate their polycrystalline nature. The intense diffraction peaks located at $2 \theta=12.74^{\circ}, 25.66^{\circ}$ and $38.93^{\circ}$ are related to the $\left(\begin{array}{lll}0 & 2 & 0\end{array}\right),\left(\begin{array}{lll}0 & 4 & 0\end{array}\right)$ and ( $\left.\begin{array}{lll}0 & 6 & 0\end{array}\right)$ reflections of orthorhombic structured $\alpha$ phase $\mathrm{MoO}_{3}$. The weak diffraction peaks seen at $23.37^{\circ}, 27.32^{\circ}$ and $49.26^{\circ}$ correspond to the $\left(\begin{array}{lll}0 & 1 & 1\end{array}\right)$, $\left(\begin{array}{lll}0 & 2 & 1\end{array}\right)$ and $\left(\begin{array}{lll}0 & 0 & 2\end{array}\right)$ reflections of $\beta$-phase $\mathrm{MoO}_{3}$. It indicates that the films formed at low sputtering pressure of $2 \mathrm{~Pa}$ are of predominately of ( $0 \mathrm{k} 0$ ) orientation of $\alpha$-orthorhombic phase along with monoclinic $\beta$-phase $\mathrm{MoO}_{3}$. As the sputtering pressure was increased to $4 \mathrm{~Pa}$, the films diffraction reflections ( $\left(\begin{array}{lll}0 & 2 & 0\end{array}\right)$ and $\left(\begin{array}{lll}0 & 4 & 0\end{array}\right)$ of $\alpha$-phase $\mathrm{MoO}_{3}$ embedded in the amorphous matrix have appeared. The lattice parameters calculated for the $\alpha$-phase $\mathrm{MoO}_{3}$ films are $\mathrm{a}=0.3923 \mathrm{~nm}, \mathrm{~b}=1.3768 \mathrm{~nm}$ and $\mathrm{c}=3.769 \mathrm{~nm}$ which is in good agreement with JCPDS Card No. 76-1003. With further increase of the sputtering pressure to $6 \mathrm{~Pa}$, the intensity of the (0 20 ) and $(040)$ reflections of $\alpha-\mathrm{MoO}_{3}$ decreased which indicates that the smaller size crystallites are embedded in the amorphous matrix. The decrease of crystallinity with the increase of sputtering pressure may be due to the decrease in plasma density with lower charging efficiency.

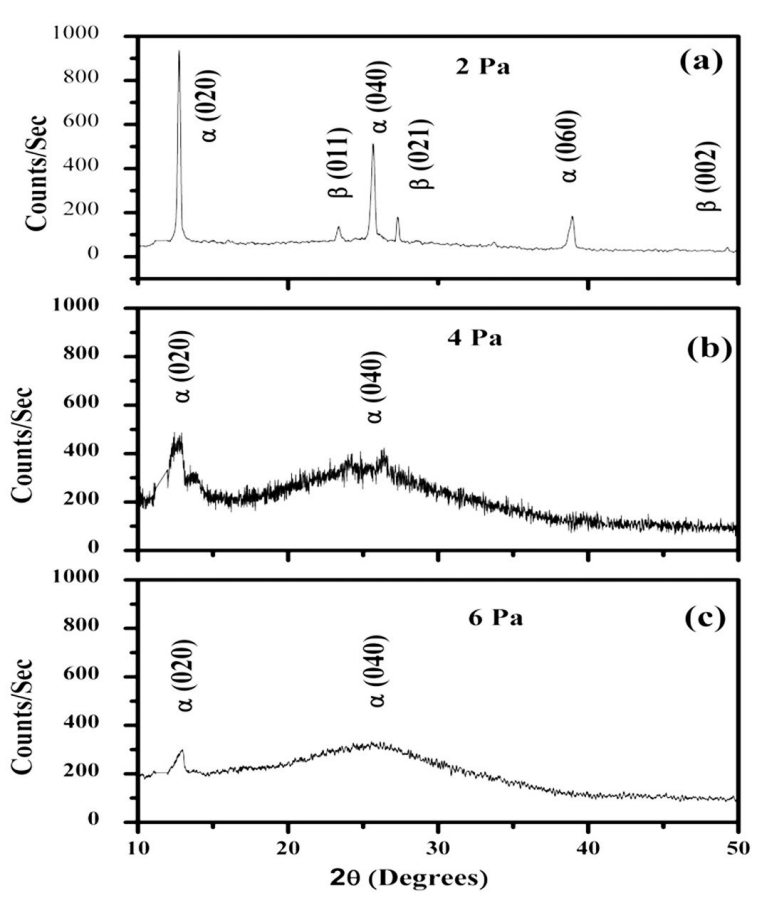

Fig. 3. XRD profiles of $\mathrm{MoO}_{3}$ films formed at different sputtering pressures.

At high sputtering pressures the mean free path of the sputtered species is low, thereby an increase in the number of collisions leads to the growth of larger size clusters [43]. The crystallite size (D) of the films was calculated by using the DebyeScherrer relation [44]:

$$
D=0.89 \lambda / \beta \cos \theta
$$


where $\lambda$ is the X-ray wavelength, 0.89 is the correction factor for copper $\mathrm{X}$-ray radiation and $\theta$ the diffraction angle. The crystallite size of the $\mathrm{MoO}_{3}$ films decreased from $45 \mathrm{~nm}$ to $16 \mathrm{~nm}$ with the increase of sputtering pressure from $2 \mathrm{~Pa}$ to $6 \mathrm{~Pa}$ due to the decrease in the crystallinity of the films.

\subsection{Surface morphology}

Fig. 4 shows the scanning electron micrographs of the $\mathrm{MoO}_{3}$ films deposited at different sputtering pressures. The micrographs show a change in surface morphology of the films with the increase of sputtering pressure.

At low sputtering pressure of $2 \mathrm{~Pa}$, the $\mathrm{MoO}_{3}$ films exhibit needle like structured grains with a length of $400 \mathrm{~nm}$ and diameter of about $150 \mathrm{~nm}$. The surface of the films formed at sputtering pressure of $4 \mathrm{~Pa}$ exhibits a loosely packed structure with smaller grain size. This may be due to the fact that more intensive argon ion bombardment causes a reduction of adatoms mobility, hence, smaller size of the grains. At higher sputtering pressure of $6 \mathrm{~Pa}$, the films show the dense structure. It reveals that the films formed at sputtering pressure of $2 \mathrm{~Pa}$ are composed of larger size grains with a needle structure. Yang et al. [45] noticed the formation of platelets type crystallites that were uniformly distributed in the films.

\subsection{Fourier transforms infrared spec- troscopy}

Fourier transform infrared transmittance (FT-IR) spectra of $\mathrm{MoO}_{3}$ films were recorded on the films deposited on silicon substrates in the wavenumber range of $400 \mathrm{~cm}^{-1}$ to $1500 \mathrm{~cm}^{-1}$. Fig. 5 shows the FT-IR spectra of $\mathrm{MoO}_{3}$ films formed at sputtering pressures of $2 \mathrm{~Pa}$ and $4 \mathrm{~Pa}$. The FT-IR spectra show a broad absorption band in the wavenumber range of $600 \mathrm{~cm}^{-1}$ to $1000 \mathrm{~cm}^{-1}$. The films formed at low sputtering pressure of $2 \mathrm{~Pa}$ exhibit weak absorption bands at $985 \mathrm{~cm}^{-1}$, $805 \mathrm{~cm}^{-1}, 663 \mathrm{~cm}^{-1}$ and $560 \mathrm{~cm}^{-1}$. The absorption bands seen at $985 \mathrm{~cm}^{-1}$ are related to the stretching vibration mode of $\mathrm{Mo}=\mathrm{O}[46,47]$, at $805 \mathrm{~cm}^{-1}$ are related to the stretching vibrations of $\mathrm{Mo}=\mathrm{O}$ and at $663 \mathrm{~cm}^{-1}$ correspond to the

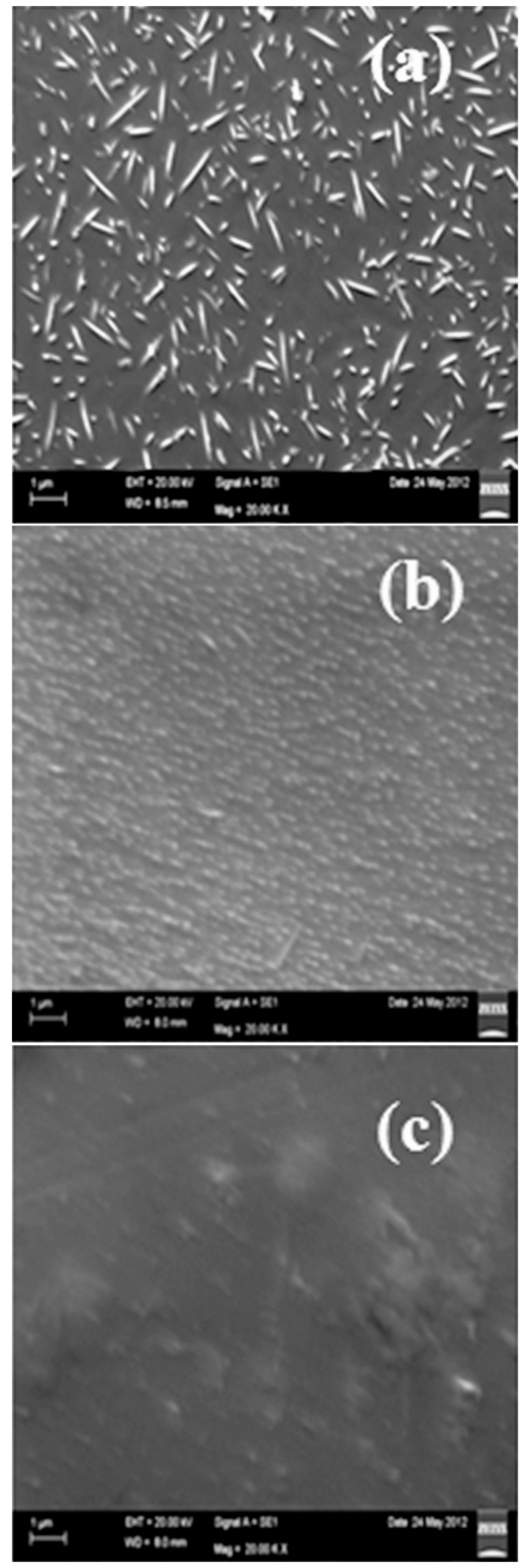

Fig. 4. SEM images of $\mathrm{MoO}_{3}$ films formed at sputtering pressures: (a) $2 \mathrm{~Pa}$, (b) $4 \mathrm{~Pa}$ and (c) $6 \mathrm{~Pa}$.

stretching vibration of Mo-O. The band located at $560 \mathrm{~cm}^{-1}$ is related to the transverse optical vibration mode of Mo-O-Mo [48]. In the case 

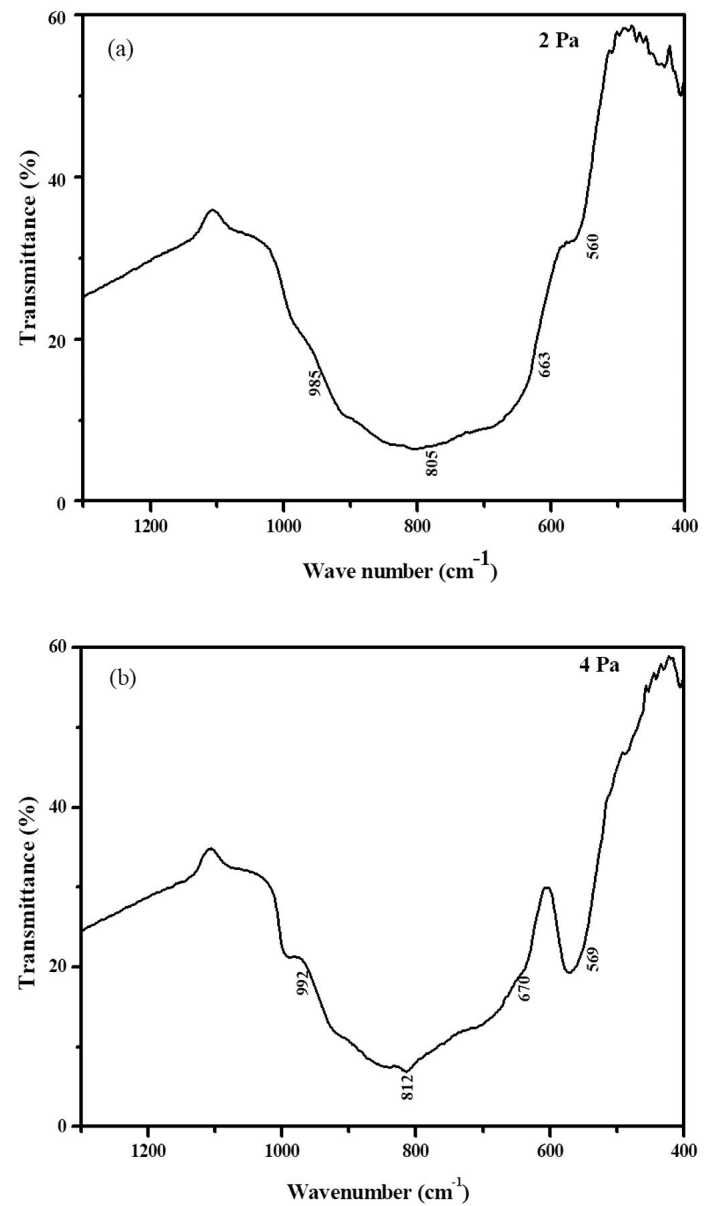

Fig. 5. FT-IR transmittance spectra of $\mathrm{MoO}_{3}$ films formed at sputtering pressures of $2 \mathrm{~Pa}$ and $4 \mathrm{~Pa}$.

of films deposited at sputtering pressure of $4 \mathrm{~Pa}$ the absorption bands are observed at $992 \mathrm{~cm}^{-1}$, $812 \mathrm{~cm}^{-1}, 670 \mathrm{~cm}^{-1}$ and $569 \mathrm{~cm}^{-1}$. The intensity of the absorption bands increased in these films. The absorption band located at $992 \mathrm{~cm}^{-1}$ is the characteristic vibration of $\mathrm{Mo}=\mathrm{O}$ in $\mathrm{Mo}^{6+}$ of $\alpha$-phase $\mathrm{MoO}_{3}$ [47, 49, 50]. The band located at $569 \mathrm{~cm}^{-1}$ is ascribed to transverse optical vibration of Mo-O-Mo. It clearly indicates that the films formed at sputtering pressure of $4 \mathrm{~Pa}$ are composed of $\alpha$-phase $\mathrm{MoO}_{3}$.

\subsection{Electrical properties}

The electrical resistivity of the films formed on the glass substrate was measured by employing four probe method. The films formed at low sputtering pressure of $2 \mathrm{~Pa}$ showed the electrical resistivity of $6.0 \times 10^{4} \Omega \cdot \mathrm{cm}$. As the sputtering pressure increased to $4 \mathrm{~Pa}$, the resistivity of the films decreased to $1.6 \times 10^{4} \Omega \cdot \mathrm{cm}$ and at high sputtering pressure of $6 \mathrm{~Pa}$ remained almost constant with the value of about $2.0 \times 10^{4} \Omega \cdot \mathrm{cm}$. High resistivity observed in the films formed at low sputtering pressure was due to the growth of mixed phase of $\alpha$ - and $\beta$-phase $\mathrm{MoO}_{3}$, whereas those formed at sputtering pressure of $4 \mathrm{~Pa}$ was due to single phase $\alpha$-phase $\mathrm{MoO}_{3}$. Sabhapathi et al. [25] obtained electrical resistivity of $5 \times 10^{4} \Omega \cdot \mathrm{cm}$ in electron beam deposited $\alpha$-phase $\mathrm{MoO}_{3}$ films. Yang et al. [45] also noticed lower electrical resistivity in $\alpha$-phase $\mathrm{MoO}_{3}$ films formed at substrate temperature of $573 \mathrm{~K}$ and $\beta$-phase films formed at $473 \mathrm{~K}$ in electron beam deposition process.

\subsection{Optical properties}

Fig. 6 shows the optical transmittance spectra of $\mathrm{MoO}_{3}$ films deposited on glass substrate at different sputtering pressures. The optical transmittance of the films formed at the sputtering pressure of $2 \mathrm{~Pa}$ (at wavelengths above $600 \mathrm{~nm}$ ) is about $85 \%$. As the sputtering pressure increased to $6 \mathrm{~Pa}$ the transmittance of the films decreased to $60 \%$. The decrease in transmittance with the sputtering pressure is due to an increase in oxygen ion vacancies. When the sputtering pressure increased, the optical absorption edge shifted towards higher wavelength side. Optical absorption coefficient $(\alpha)$ was calculated from the optical transmittance (T) and thickness (d) of the films using the relation:

$$
\alpha=-(1 / d) \ln T
$$

The optical band gap was calculated using the Tauc relation [51], assuming that the direct transitions take place in the films:

$$
\alpha h v=A(h v-E g)^{1 / 2}
$$

where hv is photon energy, Eg the optical band gap. Extrapolation of the Tauc plot of $(\alpha h v)^{2}$ versus photon energy (hv) gives the optical band gap of the films. The optical band gap of the films formed at the sputtering pressure of $2 \mathrm{~Pa}$ was $3.12 \mathrm{eV}$. As 


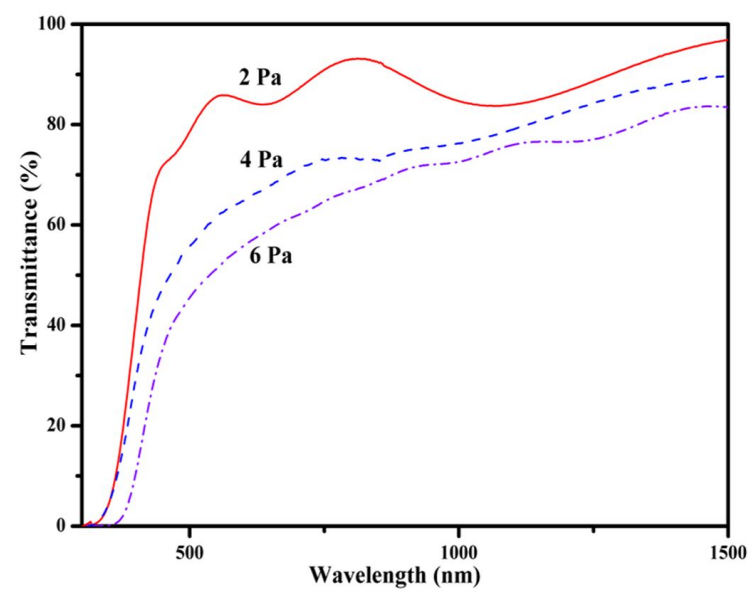

Fig. 6. Optical transmittance spectra of $\mathrm{MoO}_{3}$ films formed at different sputtering pressures.

the sputtering pressure increased to $4 \mathrm{~Pa}$, the optical band gap decreased to $3.05 \mathrm{eV}$ and at $6 \mathrm{~Pa}$ it was $2.86 \mathrm{eV}$. It is to be mentioned that the optical band gap of the electron beam evaporated films was $3.16 \mathrm{eV}$ [52] and $3.15 \mathrm{eV}$ in chemical vapor deposited films [50].

\section{Conclusions}

Thin films of $\mathrm{MoO}_{3}$ were deposited on glass and silicon substrates held at temperature of $473 \mathrm{~K}$ by RF magnetron sputtering of molybdenum target at an oxygen partial pressure of $4 \times 10^{-2} \mathrm{~Pa}$ and at different sputtering pressures in the range of $2 \mathrm{~Pa}$ to $6 \mathrm{~Pa}$. The influence of sputtering pressure on the structure, electrical and optical properties of $\mathrm{MoO}_{3}$ films was investigated. Energy dispersive X-ray analysis revealed that the films deposited at the sputtering pressure of $4 \mathrm{~Pa}$ were composed of $\mathrm{MoO}_{3}$. X-ray diffraction studies of the films revealed the growth of predominant $\alpha$ $\mathrm{MoO}_{3}$ at the sputtering pressure of $4 \mathrm{~Pa}$. Fourier transform infrared spectroscopic studies confirmed the presence of characteristic vibration modes of $\mathrm{Mo}=\mathrm{O}$ and $\mathrm{Mo}-\mathrm{O}-\mathrm{Mo}$ related to the $\mathrm{MoO}_{3}$. Crystallite size of the films decreased from $45 \mathrm{~nm}$ to $16 \mathrm{~nm}$ with the increase of sputtering pressure from $2 \mathrm{~Pa}$ to $6 \mathrm{~Pa}$. Microstructure analysis of the films revealed a change in surface morphology from a needle-like structure to a dense structure in the films obtained in the sputtering pressure range of investigation. Electrical resistivity of the films decreased from $6.0 \times 10^{4} \Omega \cdot \mathrm{cm}$ to $2.0 \times 10^{4} \Omega \cdot \mathrm{cm}$ with the increase of sputtering pressure from $2 \mathrm{~Pa}$ to $6 \mathrm{~Pa}$. The optical transmittance of the deposited films was about $85 \%$ at low sputtering pressure of $2 \mathrm{~Pa}$ and it decreased at higher sputtering pressures. Optical band gap of the films decreased from $3.12 \mathrm{eV}$ to $2.86 \mathrm{eV}$ with the increase of sputtering pressure from $2 \mathrm{~Pa}$ to $6 \mathrm{~Pa}$, respectively. In conclusion, $\alpha$-phase $\mathrm{MoO}_{3}$ films with electrical resistivity of $1.6 \times 10^{4} \Omega \cdot \mathrm{cm}$ and an optical band gap of $3.05 \mathrm{eV}$ were achieved at the sputtering pressure of $4 \mathrm{~Pa}$.

\section{Acknowledgements}

One of the authors, Dr. S. Uthanna, is thankful to the University Grants Commission, New Delhi, India, for the award of UGC-BSR Faculty Fellowship.

\section{References}

[1] Touihri S., Arfaoui A., TArchouna Y.A., Labidi M., Amlouk J.C., Berned E., Appl. Surf. Sci., 394 (2017), 414.

[2] Nivas I., Heinz K., Thomas T., Mathias S., MaHadevan Pillai V.P., Sens. Actuators B, 187 (2013), 611

[3] Mhamdi A., Labidi A., Souissi B., Kahlaoui M., YUMAK A., BoubaKer K., AMLOUK A., AMLOUK M., J. Alloy Compd., 639 (2015), 648.

[4] Buono-Core G.E., Kahn A.K., Castillo C., Munoz E., Manzur C., Cabello G., Chornik B., J. Non-Cryst. Solids, 387 (2014), 21.

[5] Bai S., Chen C.H., Tain Y., Chen S., Luo R., Li D., ACHEN A., LIU C.C., Mater. Res. Bull., 64 (2015), 252.

[6] Li Y.X., Song Z.X., Jiang F., Sun Q., Wang H.R., CHEN K., Ceram. Int., 42 (2016), 18318.

[7] Chen J., Wang M., LiU X., Zhang J., Ding L., Gao L., Li Y., J. Alloy. Compd., 619 (2015), 406.

[8] Galatsis K., Li Y.X., Wlodarski W., KalantarZADER K., Sensors Actuat. B, 77 (2001), 478.

[9] Julien C.M., Lithium Batteries: New Materials Development and Prospective, Pistonia Edition, North Holland, 1994.

[10] Zhou L., Yuan L., Zou J., Yu C., Phys. C: Chem. C, 144 (2010), 21868.

[11] Chen Y., Lu C., Xu I., Ma Y., Hou W., Zhu J., Cryst. Eng. Commun., 12 (2010), 3740.

[12] Manivel A., Lee G.L., Lee C.Y., Chen C.Y., Chen JH., Ma S.S., Horng T.L., Wu J.J., Mater. Res. Bull., 62 (2015), 184.

[13] Scarminio J., Lourenco A., Gorenstein A., Thin Solid Films, 302 (1997), 66. 
[14] Sobiraj R.T., Hermann K., Witko M., Blume A., Mestl G., Schlogi R., Appl. Surf. Sci., 489 (2001), 107.

[15] Lin S.Y., Wang C.M., KaO S.K., Chen Y.C., LiU C.C., Sol-Gel J. Sci. Technol., 53 (2010), 51.

[16] Cheturvedi N., Kumar Swamy S., Dutta V., Solar Energy, 137 (2016), 379.

[17] FAN X., FANG G., QIN P., SUn N., LiU N., HANG Q., Cheng F., Yuan L., Zhao X., Phys J., D: Appl. Phys., 44 (2011), 045101.

[18] Upama M.B., Wright M., Elumalai N.K., MaHAMUd M.A., WANG D., CHEN K.H., XU C., Haque F., Uddin A., Curr. Appl. Phys., 17 (2017), 298.

[19] LiU R., Xu C., Biswas R., Shinar J., Shinar R., Appl. Phys. Lett., 99 (2011), 093305.

[20] Zadsar M., Fallah H.R., Mahmoodzadeh M.H., Tabatabaei S.V., Lumin. J. Sci., 132 (2012), 992.

[21] Yang H., Kim J., Yamamato K., Hosono H., Org. Electronics, 46 (2017), 133.

[22] Al-Kuhaili M.F., Ahmad S.H.A., DURRANi S.M.A., Faiz M.M., Ul-Hamid A., Mater. Des., 73 (2015), 15

[23] Cho J.M., Lee S.K., Moon S.J., Jo J., Shin W.S., Curr. Appl. Phys., 14 (2014), 1144.

[24] Senthil Kumar R., Ananda Babu G., MaHalingam T., RaVi G., Energy Chem. J., 25 (2016), 798.

[25] Sabhapathi V.K., Hussain MD.O., Reddy P.S., REDDY K.T.R.K., NAIDU B.S., UTHANNA S., REDDY P.J., Phys. Stat. Solidi A, 148 (1995), 167.

[26] Al-Kuhaili M.F., Durrani S.M.A., BaKhtiari I.A., Al-Shukri A.M., Opt. Commun., 283 (2010), 2857.

[27] PARdo A., Torres J., Thin Solid Films, 520 (2012), 1709.

[28] Quintana A., Varee A., Guerrero M., SuniNACh S., Baro M.D., Sort J., Pellicer E., Electrochimica Acta, 173 (2015), 705.

[29] Patil R.S., Uplane M.D., Patil P.S., Appl. Surf. Sci., 252 (2006), 8050

[30] Martinez H.M., Torres J., Lopez Correno L.D., GARCIA M.E.R., Mater. Charact., 25 (2013), 253.

[31] Pandeswari R., Jeyaprakash B.G., BIOSENS. Biochem., 53 (2014), 182.

[32] Afify H.H., Hassan S.A., Abouelsayed A., Demian S.E., ZaYed H.A., Thin Solid Films, 623 (2017), 40
[33] Bouchachem A., Bouzidi C., Boughalmi R., Ouerteni R., Khlaoui M., Ouni B., Elhouichet M., Amlouk M., Ceram. Int., 40 (2014), 13427.

[34] Miao Y., Lu G., LiU X., Guo Y., Wang Y., Guo Y., MOL J.. Cat. A, 306 (2009), 17.

[35] Dhanasankar M., Purushothaman K.K., MuRalidharan G., Appl. Surf. Sci., 257 (2011), 2074.

[36] Mutta G.R., Popuri S.R., Wilson J.I.B., Bennet N.S., Solid State Sci., 61 (2016), 84.

[37] Aravinda L.S., Nagaraja K.K., Udaya Bhat K., R. AmACHANDRA BHAT B., J. Electroanal. Chem., 699 (2013), 28

[38] Shimizu R., Yamamoto K., Suzuki T.T., OHSaWa T., Hitosugi T., Thin Solid Films, 595 (2015), 153.

[39] Nirupama V. Uthanna S., J. Mater. Sci: Mater. Electron., 27 (2016), 3668

[40] Cheng F., Fang G., Fan X., Huang H., Zhang Q., QIN P., LEI H., Sol. Energ. Mater. Sol. C., 110 (2013), 63.

[41] Gretener C., Perrenoud J., Kranz L., BaechLer C., Yoon S., Romanyuk Y.E., Buecheler S., Tiwari A.N., Thin Solid Films, 535 (2013), 193.

[42] Subbarayudu S., Madhavi V., Uthanna S., $A d v$. Mater. Lett., 4 (2013), 637.

[43] Barnes M.C., Kumar S., Green L., Huang N.M. GERSON A.R., Surf. Coat. Technol., 190 (2005), 321.

[44] Cullity B.D, Stock S.R., Elements of X-Ray Diffraction, $3^{\text {rd }}$ Ed., Prentice Hall Inc., New Jersey. 2001.

[45] Yang W.Q., Wei Z.R., Zhu X.H., Yang D.Y., Phys. Lett. A, 373 (2009), 3965.

[46] SRinivasarao S.R., Rajinikanth B., MukhopadHYAY P.K., Appl. Phys. A, 9 (2009), 985.

[47] NaZRi G.A., Julien C.M., Solid State Ionics, 133 (1992), 376

[48] Nivas I., Vinod Kumar R., Lethy K.J., Detty A.P., Ganesan V., Sathe V., Mahadevan Pillai V.P., J. Phys. D: Appl. Phys., 42 (2009), 175305.

[49] Nirupama V., Gunasekhar K.R., Sreedhar B., Uthanna S., Curr. Appl. Phys., 10 (2010), 272.

[50] Sain T S., Reddy G.B., J. Appl. Phys., 98 (2005), 026104.

[51] TAUC J., Amorphous and Liquid Semiconductors, Plenum Press, New York, 1974.

[52] LeE Y.J., Nichols W.T., KIM D.G., KiM Y.D., $J$. Phys. D: Appl. Phys., 42 (2009), 115419.

Received 2017-08-17 Accepted 2019-04-23 